Full length article

\title{
Chicken line-dependent mortality after experimental infection with three type IIxIII recombinant Toxoplasma gondii clones
}

\author{
G. Schares a, *, D.C. Herrmann a , P. Maksimov a , B. Matzkeit ${ }^{\text {a }}$, F.J. Conraths a , G. Moré a, b, \\ R. Preisinger ${ }^{c}$, S. Weigend ${ }^{\mathrm{d}}$ \\ ${ }^{a}$ Friedrich-Loeffler-Institut, Institute of Epidemiology, Südufer 10, 17493 Greifswald-Insel Riems, Germany \\ ${ }^{\mathrm{b}}$ Consejo Nacional de Investigaciones Cientificas y Técnicas (CONICET), Buenos Aires, Argentina \\ ${ }^{c}$ Lohmann Tierzucht GmbH, Cuxhaven, Am Seedeich 9-11, 27472 Cuxhaven, Germany \\ ${ }^{\mathrm{d}}$ Friedrich-Loeffler-Institut, Institute of Farm Animal Genetics, Hoeltystrasse 10, 31535 Neustadt, Germany
}

\section{H I G H L I G H T S}

- Four chicken lines differing in performance level and phylogenetic origin were used for $T$. gondii infection experiments.

- Virulence of one type IIxIII recombinant $T$. gondii clone was different in mice and one-day old chickens.

- Only one of two mouse-virulent type IIxIII recombinant $T$. gondii clones caused mortality in chicks.

- Increased mortality in chicks due to toxoplasmosis affected only white layers (R11, WLA).

- R11 chicks had significantly lower anti-TgSAG1 antibody (IgY) levels as compared to chicks from other layer lines.

\section{A R T I C L E I N F O}

\section{Article history:}

Received 22 September 2016

Received in revised form

11 November 2016

Accepted 27 November 2016

Available online 29 November 2016

\section{Keywords:}

Toxoplasma gondii

Sexual recombination

Chicken

Mouse

Virulence

Antibody response
G R A P H I C A L A B S T R A C T

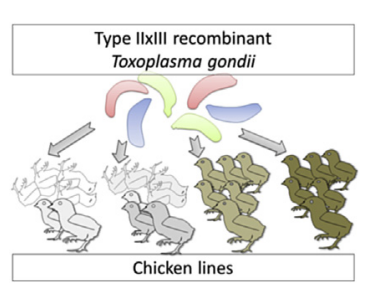

\footnotetext{
* Corresponding author.

E-mail address: gereon.schares@fli.de (G. Schares).
} 
high chicken virulence. This was in agreement with the parasite load as determined by real-time PCR Overall, results show that progeny resulting from natural sexual recombination of $T$. gondii clonal lineages, may differ in their virulence for mice and chickens.

๑) 2016 Elsevier Inc. All rights reserved.

\section{Introduction}

Toxoplasma gondii ( $T$. gondii) is an obligate intracellular protozoan parasite, that has an extremely wide host range and is able to infect virtually all warm-blooded host species, including mammal and avian animals. Felines are definitive hosts of $T$. gondii, i.e. this protozoan is able to sexually multiply and recombine in the feline intestine. Felines, including domestic cats are able to shed several hundred millions of oocysts via their feces into the environment (Dubey, 2010b).

The global population structure of $T$. gondii is very diverse and differs among continents. However, its differential appearance in various parts of the world is only partially understood. While two major clonal lineages (type II and III) dominate clinical and natural isolates in Europe and North America (Ajzenberg, 2015; Ajzenberg et al., 2004), other parts of the world like South America (especially Brazil) are dominated by non-clonal or other clonal $T$. gondii lineages representing a greater genetic diversity of $T$. gondii (Shwab et al., 2014). As yet, 15 haplogroups of T. gondii have been reported worldwide (Su et al., 2012) but the existence of as yet unknown haplogroups is expected in more remote areas of the globe (Ajzenberg, 2015). It has been hypothesized that genetic diversity in $T$. gondii is driven by selective pressures due to its adaptation to different intermediate or definitive hosts, which are included in domestic and sylvatic life cycles in different parts of the world (VanWormer et al., 2014).

T. gondii is known to infect a large spectrum of avian species, which ranges from passeriform birds, like sparrows, to galliform birds such as chickens (Dubey, 2002). A relatively large number of clinical cases of chicken toxoplasmosis has been reported several decades ago, occasionally in combination with Marek's disease (Beauregard et al., 1965; Biering-Sorensen, 1956; Erichsen and Harboe, 1953; Frankhauser, 1951; Goodwin et al., 1994; Hepding, 1939; Schellner and Vollbrechtshausen, 1955; Schulte, 1954). However, we are aware of only one recent case report (Dubey et al., 2007). Most affected chickens were adults with central nervous symptoms; histological examination often revealed encephalitis, neuritis, myocarditis and retina lesions.

Worldwide, T. gondii has been isolated from a large number of chickens without obvious symptoms (Dubey, 2010a). In some occasions up to $100 \%$ of adult backyard chickens were infected (Dubey, 2010a). Therefore, chickens are regarded as highly susceptible for infection with $T$. gondii, but hardly develop clinical disease. This was confirmed by a number of experimental infections, regardless whether adult chickens were inoculated with oocysts, bradyzoites or tachyzoites (Dubey et al., 1993; Jacobs and Melton, 1966; Kaneto et al., 1997). However, a number of studies showed that chicks or a few months old chickens were more likely to develop disease than adult chickens (Boch et al., 1966; Geißler, 1952; Geissler, 1955; Kulasiri, 1965; Simitch et al., 1961).

The effects of infection with $T$. gondii strains with differences in mouse virulence in chicks and adult hens were examined for the first time in the 1960s (Boch et al., 1966). It was not possible to genotype these strains at that time, but one of these strains, the mousevirulent BK strain, was later characterized as T. gondii type I lineage (Ajzenberg et al., 2002). This strain caused death in most i.p.-infected one-day old chicks (dose $2 \times 10^{6}$ tachyzoites, 80\% mortality), but was not virulent in adult chickens (Boch et al., 1966). When chicks were inoculated with a strain not virulent for mice (S93 strain), mortality was observed only in $13 \%$ of the chicks, while there was no mortality in hens (Boch et al., 1966). The genotype of the S93 strain is unknown. Experimental oocyst infections of White Leghorn chickens also suggested a higher virulence of $T$. gondii type I (strain GT-1) as compared to type II (strain ME 49) infection (Dubey et al., 1993). Recent experiments with 10-day old broiler chicks using the T. gondii strain RH and four other T. gondii strains isolated from different hosts in China revealed differences in survival times for chickens infected i.p. at doses of $1 \times 10^{8}$ or $5 \times 10^{8}$ tachyzoites. The shortest survival times were observed in broiler chicks infected with a T. gondii strain isolated from chicken (Wang et al., 2015).

Differences in acute mouse virulence between $T$. gondii clonal lineages (i.e., types I, II and III) can be explained by varying parasitedriven effects on the immunoreactions of the infected host or host cells, e.g. by interference with the p47 GTPase-mediated killing of intracellular tachyzoites (Khaminets et al., 2010), production of IL12 (Robben et al., 2004), MAPK signaling (Peixoto et al., 2010), NF$\mathrm{kB}$ signaling (Dobbin et al., 2002), or induction and sustenance of JAK/STAT signaling (Saeij et al., 2007). Known T. gondii proteins mediating these effects are rhoptry kinases (ROPKs) like ROP18 (Saeij et al., 2006; Taylor et al., 2006), ROP16 (Rosowski et al., 2011; Saeij et al., 2007), or ROP38 (Peixoto et al., 2010), which are either polymorphic (Fentress et al., 2010; Saeij et al., 2007; Steinfeldt et al., 2010) or differentially expressed (Peixoto et al., 2010; Saeij et al., 2006; Taylor et al., 2006) among T. gondii type I, II and III strains and are accepted as virulence factors of this protozoon. Since the avian immune system shows fundamental differences to the immune system of mammals, it was expected that virulence of $T$. gondii in mice is not necessarily associated with virulence in chickens (Ong et al., 2011). Moreover, it was hypothesized that adaptation of $T$. gondii strains to avian intermediate hosts and their immune systems may have been involved in the establishment of one or several of the clonal linages dominating in Europe or North America (Ong et al., 2011).

The aim of this study was to investigate the virulence of natural type IIxIII recombinant T. gondii clones in chicks and to compare the results with findings in $\mathrm{BALB} / \mathrm{c}$ mice. It was expected that virulence characteristics of some of these clones would differ between mice and chickens. Due to differences of susceptibility of different mouse strains to toxoplasmosis (Araujo et al., 1976) and wide phylogenetic divergences of the chicken lines (Granevitze et al., 2009; Lyimo et al., 2014), we decided to perform the experiments using commercial breeding lines of white and brown layers selected for high egg-production (WLA, BLA, respectively) in comparison to lowperforming white and brown-layer genotypes (R11, L68, respectively), which were obtained from non-selected resource populations of the Friedrich-Loeffler-Institut (FLI) (Lieboldt et al., 2015).

\section{Material and methods}

\subsection{Parasites}

For experimental infection, three of the T. gondii clones (K119/2 
2C10, B136/1 B6H6, K119/2 A7) were used, which have been isolated and previously described by our working group (Herrmann et al., 2012). PCR-RFLP genotyping (Herrmann et al., 2010) based on nine independent, unlinked genetic markers revealed that these three clones represented type IIxIII recombinant $T$. gondii clones (Table 1). All parasites clones have previously been characterized for mouse virulence (Herrmann et al., 2012). However, since clones had been further passaged for several months by cell cultivation, mouse virulence was re-examined. Cell cultivation was performed in Vero or MARC-145 cell lines as previously described using RPMI or DMEM as medium supplemented with $1 \%$ antibiotic solution (10,000 IU penicillin and 10,000 $\mu \mathrm{g}$ streptomycin/ml), 2\% fetal calf serum (FCS) and non-essential amino acids. Twice or three times a week, cells were split and culture media changed depending on the growth rate. In the following, clones K119/2 2C10, K119/2 A7 and B136/1 B6H6 are referred to as $2 \mathrm{C} 10, \mathrm{~A} 7$ and $\mathrm{B} 6 \mathrm{H} 6$, respectively.

\subsection{Typing T. gondii by PCR-RFLP}

Strain typing was performed to confirm the identity of inoculated parasites from chicken tissues after PCR amplification of nine independent, unlinked genetic markers, i.e. nSAG2, SAG3, BTUB, GRA6, c22-8, c29-2, L358, PK1 and Apico, followed by fragmentation with restriction enzymes of PCR-amplified marker regions as described previously (Herrmann et al., 2010).

To further characterize parasite clones used for experimental infection, additional marker regions were analysed (L339, AK 104, AK154, AK66, SRS4) and primer pairs and restriction enzymes were selected based on information provided at http://www. toxomap.wustl.edu/Toxo_Genetic_Map_Table.html. Amplifications were performed as described (Herrmann et al., 2010). Restriction enzymes were purchased from Fermentas, St. Leon-Rot, Germany, or Fisher Scientific, Schwerte, Germany, and used as recommended by the suppliers. Three $T$. gondii reference strains (RH, ME49 and NED) were included in each PCR-RFLP run.

\subsection{Animals}

\subsubsection{Mice}

Two to three-month old BALB/c mice provided by the animal facility of the FLI (Greifswald - Insel Riems, Germany) were used for intra-peritoneal (i.p.) experimental infections.

\subsubsection{Chicken lines}

One-day old chicks were used for i.p. experimental infections. Two high-performing commercial genotypes, WLA (white layer line) and BLA (brown layer line) obtained from the breeding programme of Lohmann Tierzucht GmbH (Cuxhaven, Germany), and two low-performing genotypes R11 (white layer line) and L68 (brown layer line) maintained as non-selected conservation flocks at the FLI, Institute of Farm Animal Genetics, Mariensee, Germany were used in this study. R11 originated from the Cornell Line K (Cole and Hutt, 1973) and was introduced into the Institute of Farm Animal Genetics in the 1960s (Hartmann, 1987), whereas L68 is a New Hampshire line, which was founded in the 1970s in the former German Democratic Republic (Volkseigenes Gut Vogelsang). The phylogenetically closely related lines WLA and R11 originated from the White Leghorn breed, which is distant from the Rhode Island Red high-performing BLA line and its low-performing counterpart, the New Hampshire line L68 (Lyimo et al., 2014).

\subsection{Animal experiments}

The animal experiments were evaluated by the responsible

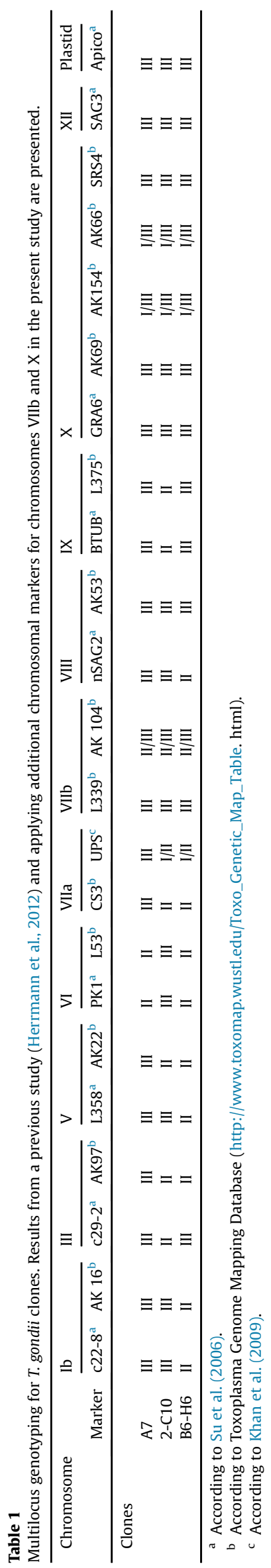


ethics committee of the German Federal State of Brandenburg and the German Federal State of Mecklenburg-Western Pomerania and gained governmental approval under the registration numbers V32347-17-2012 and LALLF M-V/TSD/7221.3-2.5-004/13. Since mouse virulence assays are usually performed by intraperitoneal inoculation of in-vitro generated tachyzoites, the same route of inoculation was also selected for the infection of chickens.

\subsubsection{Virulence of $T$. gondii clones in BALB/c mice}

Tachyzoites were grown and extracted from host cells by passage through a 27-gauge needle, washed twice in RPMI and quantified using a Neubauer chamber. Parasites were diluted in RPMI, and groups of 6-10 mice per clone inoculated i.p. with $10^{2}$ tachyzoites of each clone (in $500 \mu \mathrm{l}$ ) using a 27-gauge needle. Each in-vivo experiment was carried out alongside a negative control group. Weight and mortality of the animals were recorded daily for 30 days after infection. Mice were sacrificed at more than 20\% weight loss or at the end of the experiment, i.e. 30 days post infection (dpi). All animals were necropsied. Virulence was categorised as virulent (LD50 $<10^{2}$ tachyzoites), intermediate or not virulent (LD50 $\geq 10^{2}$ tachyzoites). At the end of the observation period, animals were humanely euthanized according to FELASA (Federation for Laboratory Animal Science Associations) regulations and blood collected. Serum samples were stored at $-20{ }^{\circ} \mathrm{C}$ until used for analysis. In the evaluation of mouse virulence, only data of mice were included that had either developed clinical disease or mounted $T$. gondii-specific antibodies, as determined by immunoblotting (Herrmann et al., 2012).

\subsubsection{Virulence of T. gondii clones in chicken}

One-day old chicks of all four chicken lines were inoculated at the same time, kept in the same room of the animal facility and supplied with the same food and water. The chicks (7-11 of each line) were inoculated i.p. with $1 \times 10^{6}$ tachyzoites of each $T$. gondii clone using a 27-gauge needle (Table 2). Fourteen chicks (lines R11,
WLA, L68) served as control groups. BLA chicks could not be included as controls because not enough chicks had been supplied on the day of infection. If a chick showed apathy and stopped drinking or taking up food it was euthanized and necropsied. Organs of the animals were collected and stored at $-20{ }^{\circ} \mathrm{C}$ until examined. At the end point of the experiment (i.e. at day 31 after infection), the remaining chickens were euthanized, blood and organs (including brain and lung) were collected and 100-500 mg samples per organ and serum samples were stored at $-20^{\circ} \mathrm{C}$ until analysis.

\subsection{Real-time PCR}

DNA was extracted from $25 \mathrm{mg}$ sample aliquots of brain and lung (remaining organs were not analysed) using a commercial kit (Tissue Kit; Macherey and Nagel, Düren, Germany) as recommended by the manufacturer. Negative processing controls were included after every $10^{\text {th }}-15^{\text {th }}$ sample during DNA extraction. Realtime PCR was performed using a previously published protocol targeting a $529 \mathrm{bp}$ repeat region with the primers ToxoTal-F (5'-TGG TTG GGA AGC GAC GAG AG-3') and ToxoTal-R ( $5^{\prime}$-CAT CAC CAC GAG GAA AGC GTC- $\left.3^{\prime}\right)$ and ToxoTal-Probe $\left(5^{\prime}-\right.$ FAM-AG $[+\mathrm{A}] \mathrm{GA}[+\mathrm{C}] \mathrm{AC}$ $[+\mathrm{C}] \mathrm{GG}[+\mathrm{A}]$ ATG CG[+A] T-BHQ1-3') (Talabani et al., 2009). The performance of the real-time PCR was controlled using positive control samples of known DNA concentration. Reactions were performed in a final volume of $20 \mu \mathrm{l}$ using a commercial mastermix (iQ supermix, Bio-Rad Laboratories GmbH, Munich, Germany) on a CFX384 thermal cycler (Biorad Laboratories $\mathrm{GmbH}$, Munich, Germany). Primers and probes were purchased from MWG-Biotech (Ebersberg, Germany) and used at standard concentrations for primers $(800 \mathrm{nM})$ and probes $(200 \mathrm{nM})$. For amplification, the reaction mixture was incubated at $50{ }^{\circ} \mathrm{C}$ for $2 \mathrm{~min}$, followed by $95^{\circ} \mathrm{C}$ for $10 \mathrm{~min}$ and then by 55 amplification cycles of $95{ }^{\circ} \mathrm{C}$ for $15 \mathrm{~s}$ and $60{ }^{\circ} \mathrm{C}$ for $1 \mathrm{~min}$ as described (Talabani et al., 2009).

Table 2

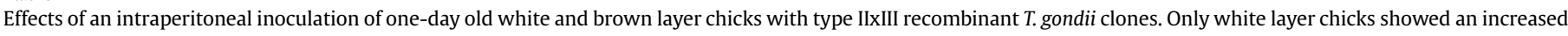
mortality when inoculated with clone 2C10.

\begin{tabular}{|c|c|c|c|c|c|c|c|}
\hline Clone used for infection & Layer type $^{\mathrm{a}}$ & Line & No. & No. survived & No. dead (dpi) & $\%$ mortality & Mortality statistically significant ${ }^{\mathrm{b}}$ \\
\hline \multirow[t]{7}{*}{ B6H6 } & & & 38 & 34 & 4 & 10.5 & NS \\
\hline & WL & & 20 & 18 & 2 & 10.0 & NS \\
\hline & & R11 & 10 & 9 & $1(30)$ & 10.0 & NS \\
\hline & & WLA & 10 & 9 & $1(17)$ & 10.0 & NS \\
\hline & $\mathrm{BL}$ & & 18 & 16 & 2 & 11.1 & NS \\
\hline & & L68 & 10 & 9 & $1(9)$ & 10.0 & NS \\
\hline & & BLA & 8 & 7 & $1(9)$ & 12.5 & NS \\
\hline \multirow[t]{7}{*}{ A7 } & & & 37 & 25 & 2 & 8.1 & NS \\
\hline & WL & & 20 & 18 & 1 & 10.0 & NS \\
\hline & & R11 & 10 & 9 & $1(8)$ & 10.0 & NS \\
\hline & & WLA & 10 & 9 & $1(22)$ & 10.0 & NS \\
\hline & $\mathrm{BL}$ & & 17 & 16 & 1 & 5.9 & NS \\
\hline & & L68 & 10 & 9 & $1(5)$ & 10.0 & NS \\
\hline & & BLA & 7 & 7 & 0 & 0.0 & NS \\
\hline \multirow[t]{7}{*}{$2 \mathrm{C} 10$} & & & 39 & 26 & 13 & 33.3 & NS \\
\hline & WL & & 21 & 10 & 11 & 52.4 & $P=0.0097$ \\
\hline & & R11 & 11 & 5 & $6(9,9,9,9,10,10)$ & 54.5 & $P=0.021$ \\
\hline & & WLA & 10 & 5 & $5(8,9,9,9,13)$ & 50.0 & $P=0.05$ \\
\hline & $\mathrm{BL}$ & & 18 & 16 & 2 & 11.1 & NS \\
\hline & & L68 & 10 & 9 & $1(2)$ & 10.0 & NS \\
\hline & & BLA & 8 & 7 & $1(9)$ & 12.5 & NS \\
\hline Controls & & R11 + WLA + L68 & 14 & 13 & $1(3)$ & 7.1 & Reference $^{c}$ \\
\hline
\end{tabular}

\footnotetext{
a WL, White layer, BL, Brown layer.

b NS, Not statistically significant, Fisher exact test.

c Controls represented reference for statistical analysis.
} 


\subsection{Antibody detection}

Specific IgG in mouse sera was determined by immunoblotting using TgSAG1, an affinity-purified cell culture-derived tachyzoite antigen (RH strain) essentially as described (Herrmann et al., 2012).

Specific IgY antibodies in chicks were quantified by ELISA, making use of affinity-purified TgSAG1. The ELISA was used as described for ducks and geese, but making use of a chicken IgY-specific peroxidase conjugate (Sigma Aldrich, Deisenhofen, Germany) at a dilution of 1:2000 (Maksimov et al., 2011). ELISA indices were calculated based on OD values determined for a sample, positive and negative control serum $\left(\mathrm{OD}_{\mathrm{S}}, \mathrm{OD}_{\mathrm{PC}}, \mathrm{OD}_{\mathrm{NC}}\right.$, respectively), applying following formula: $\left(\mathrm{OD}_{\mathrm{s}^{-}} \mathrm{OD}_{\mathrm{NC}}\right) /\left(\mathrm{OD}_{\mathrm{PC}^{-}} \mathrm{OD}_{\mathrm{NC}}\right)$. Samples that showed ELISA indices of $<0.1$ were regarded as negative.

\subsection{Statistical analysis}

The statistical software R, version 3.0.1 (R Foundation for Statistical Computing, Vienna, Austria, http://www.R-project.org) and the package "stats" were used to perform the Fisher Exact Test using the function fisher.test $(\mathrm{x})$. For pairwise comparisons between different groups and their Ct-values, or ELISA index values, the Wilcoxon rank sum test using the pairwise.wilcox.test (x) function was applied. $P<0.05$ was regarded as statistically significant.

\section{Results}

\subsection{Characterization of $T$. gondii clones by PCR-RFLP}

PCR-RFLP analysis of additional loci on chromosomes (Chr) VIIb and X revealed type III (L339, SRS4) or type I/III (AK104, AK154, AK166) alleles (Table 1).

\subsection{Mouse virulence}

When mice were inoculated with $10^{2}$ tachyzoites of $T$. gondii clone A7 (intermediate mouse virulence in previous experiments (Herrmann et al., 2012)), 7/10 (70\%) animals survived the infection (Fig. 1), while all mice died between day 9 and 15 dpi after infection with $2 \mathrm{C} 10$ and $\mathrm{B} 6 \mathrm{H} 6$ previously identified as not virulent or highly virulent, respectively (Herrmann et al., 2012).

\subsection{Survival of chickens after inoculation with T. gondii tachyzoites}

With the exception of the white layer chicks (R11, WLA) inoculated with the clone $2 \mathrm{C} 10$, mortality in all groups of chicks did not exceed $12 \%$ over the entire observation period of 31 days. Most of the chicks died between 8 and 13 dpi (Table 2).

In the R11 and WLA infected chicks, a mortality of 54.5\% (6/11) and $50.0 \%(5 / 10)$ was observed, respectively. This mortality was statistically significantly different from that observed in the control group, which was 7.1\% (1/14) (Fisher exact, $P<0.05)$ (Table 2$)$.

\subsection{Detection of T. gondii-DNA in brain and lung in chicks dying during the observation period}

All tissues collected from control animals remained negative by PCR (Table 3). Almost all brain and lung tissues of the chicks infected with 2C10 (37/39, 94.9\%) were PCR positive; 75.7\% (28/37) of the chicks infected with A7 and 57.9\% (22/38) of those inoculated with $\mathrm{B} 6 \mathrm{H} 6$ tested T. gondii-positive by PCR. All differences between these groups were statistically significant (Fisher exact, $P<0.05$ ).

In total (not stratified for survival or death during the observation period), the highest proportion of PCR-positive brain tissues were observed in chicks infected with clone 2 C10 (37/39, 92.3\%) followed by A7 infected chicks (27/37, 73.0\%) (Table 3). The lowest proportion of $T$. gondii PCR-positive chicks in brain tissues was observed in those infected with B6H6 (17/38, 44.7\%). All differences between these groups were statistically significant (Fisher exact, $P<0.05)$. The $T$. gondii specific $C t$ values in chicks dying during the observation period ranged from 11.1 to 33.1 in brain and from 10.9 to 33.3 in lung. Differences of ct values between groups were not further analysed because chicks died at different days post infection and in most of the groups the numbers of chicks that died were too low for statistical analysis.

The proportion of chicks with $T$. gondii-positive lung tissue was generally lower than the proportion of positive brain tissue as tested by PCR. The highest proportion of chicks with T. gondiipositive lungs was observed in those infected with 2C10 (29/39, $74.4 \%$ ) followed by A7 infected chicks with 21/37 (56.8\%) testing T. gondii-positive (Table 3 ). The lowest proportion of $T$. gondiipositive brain tissue was observed in B6H6 infected chicks with 13/ 38 (34.2\%). All differences between these groups were statistically significant (Fisher exact, $P<0.05$ ).

Lung was the tissue, in which also differences between chicken lines were observed. In groups of B6H6 and A7 infected R11 chicks, higher proportions of $T$. gondii PCR-positive lungs were observed than in B6H6 infected WLA and L68, or 2C10 infected BLA chicks (Table 3, Fisher exact, $P<0.05$ ).

In almost all chicks that died prior to the end of the observation period, all brains and lungs tested T. gondii DNA-positive. The lung of a L68 chick, infected with T. gondii clone 2C10, the brain of a B6H6 infected R11 chick and the lung and brain of a WLA chick, also infected with the $T$. gondii clone B6H6 remained negative for T. gondii DNA (Table 3).

\subsection{Different levels of T. gondii DNA in brain and lungs of surviving chicks}

Brain and lung samples of chicks that had survived until the end

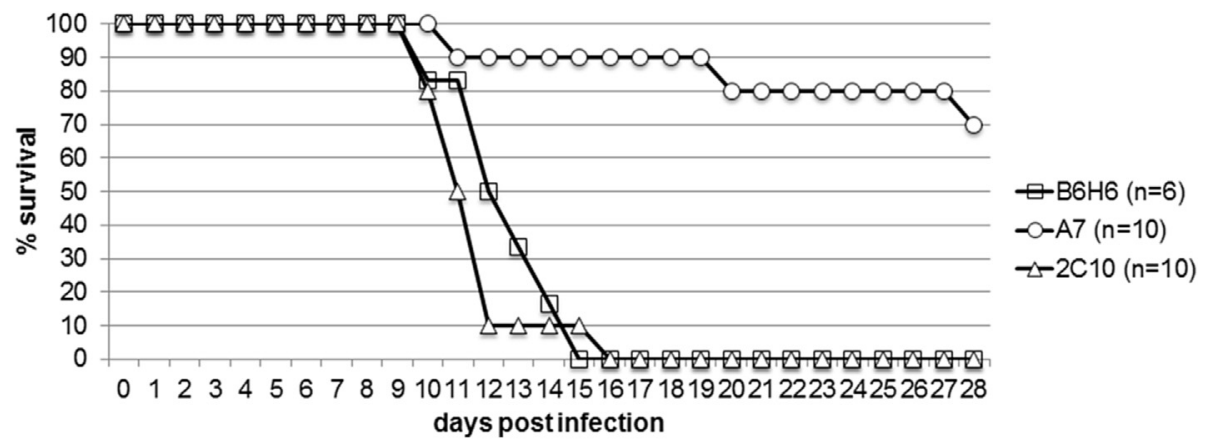

Fig. 1. Experimental intra-peritoneal infection of BALB/c mice with a dose of $10^{2}$ of three cloned $T$. gondii isolates representing type IIxIII recombinant parasites. 
Table 3

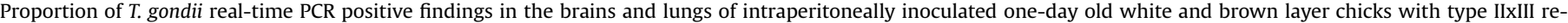

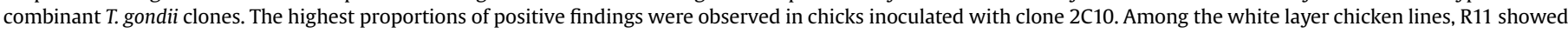
the highest proportions of $T$. gondii DNA-positive brain or lung tissue.

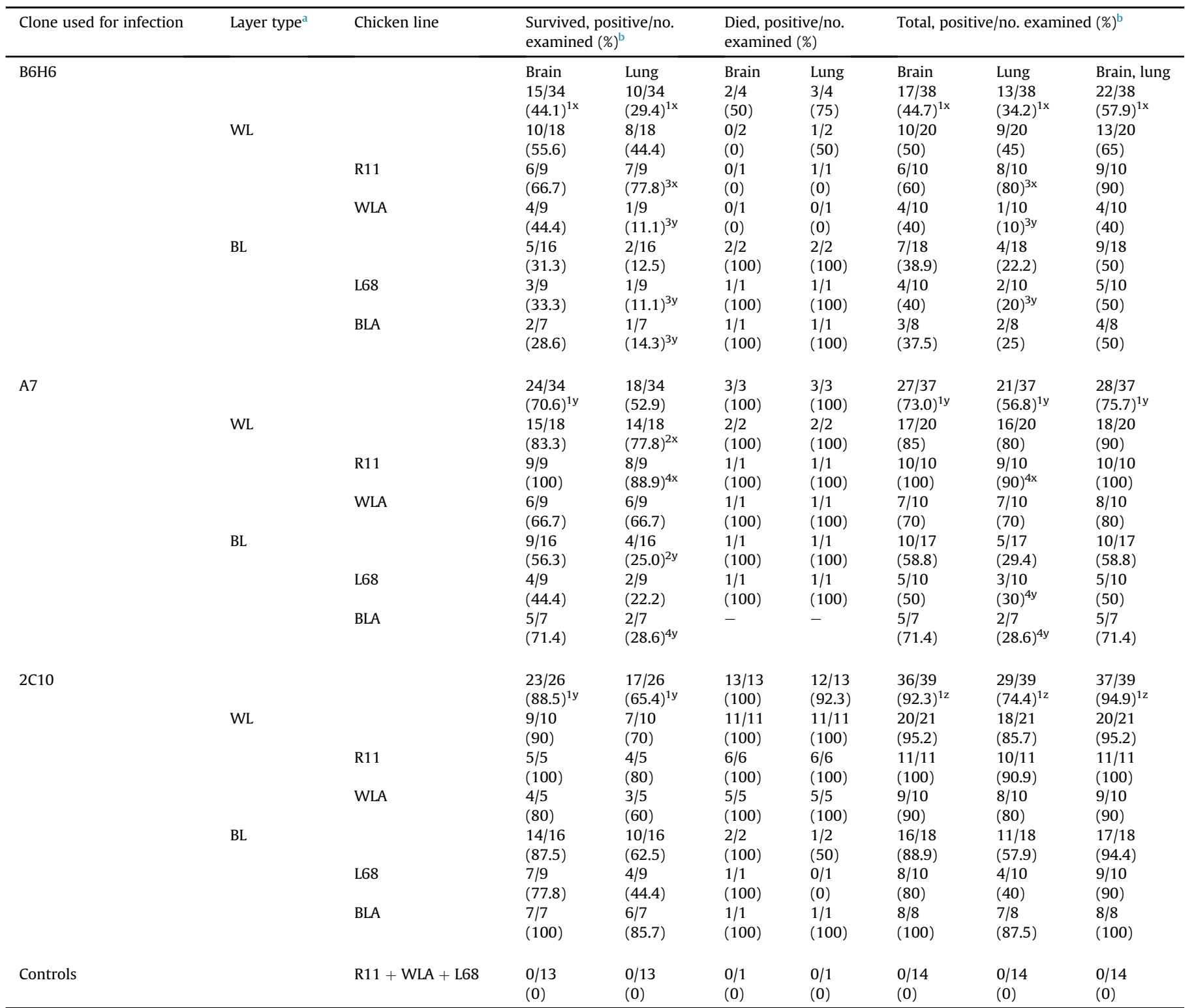

${ }^{a}$ WL, White layer, BL, Brown layer.

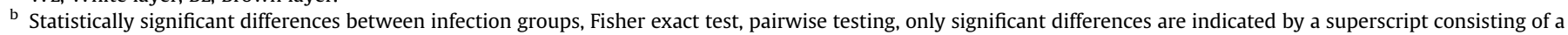

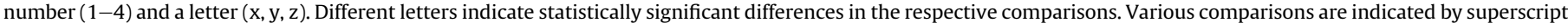

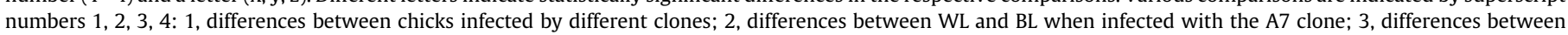
different chicken lines when infected with B6H6; 4, differences between different chicken lines when infected with A7.

of the observation period (31 dpi) were tested for the presence of T. gondii DNA by PCR. Among all chicken lines, the highest Ct values in brain tissue (indicating lowest DNA levels) were observed in chicks inoculated with B6H6 (Fig. 2A). In R11 and WLA, the difference between $\mathrm{B} 6 \mathrm{H} 6$ and $\mathrm{A} 7$ or $2 \mathrm{C} 10$ infected chicks was statistically significant (Wilcoxon rank sum test; $P<0.05$ ). In L68 chicks only the comparison between $\mathrm{B} 6 \mathrm{H} 6$ and $2 \mathrm{C} 10$ revealed a statistically significant difference (Wilcoxon rank sum test; $P<0.05$ ). The remaining comparisons revealed no statistically significant differences (Wilcoxon rank sum test; $P \geq 0.05$ ).

The $\mathrm{Ct}$ values observed in lung tissues were higher than those observed in brains (especially in the groups infected with A7 or $2 \mathrm{C} 10$, respectively). The lowest median $\mathrm{Ct}$ values from lung tissues were observed for 2C10 infected chicks in R11, WLA and BLA infected groups, while the lowest median in L68 was observed for A7 infected chicks (Fig. 2B). In none of the comparisons, a statistically significant difference was observed (Wilcoxon rank sum test; $P \geq 0.05$ ).

\subsection{Development of antibody (IgY) levels against the TG-SAG1 antigen}

Serum samples of chicks that had survived until the end of the observation period (31 dpi) were tested for antibodies directed against TG-SAG1 antigen by ELISA. All control chicks displayed ELISA indices $<0.1$ (Fig. 3). All infection groups showed significantly 

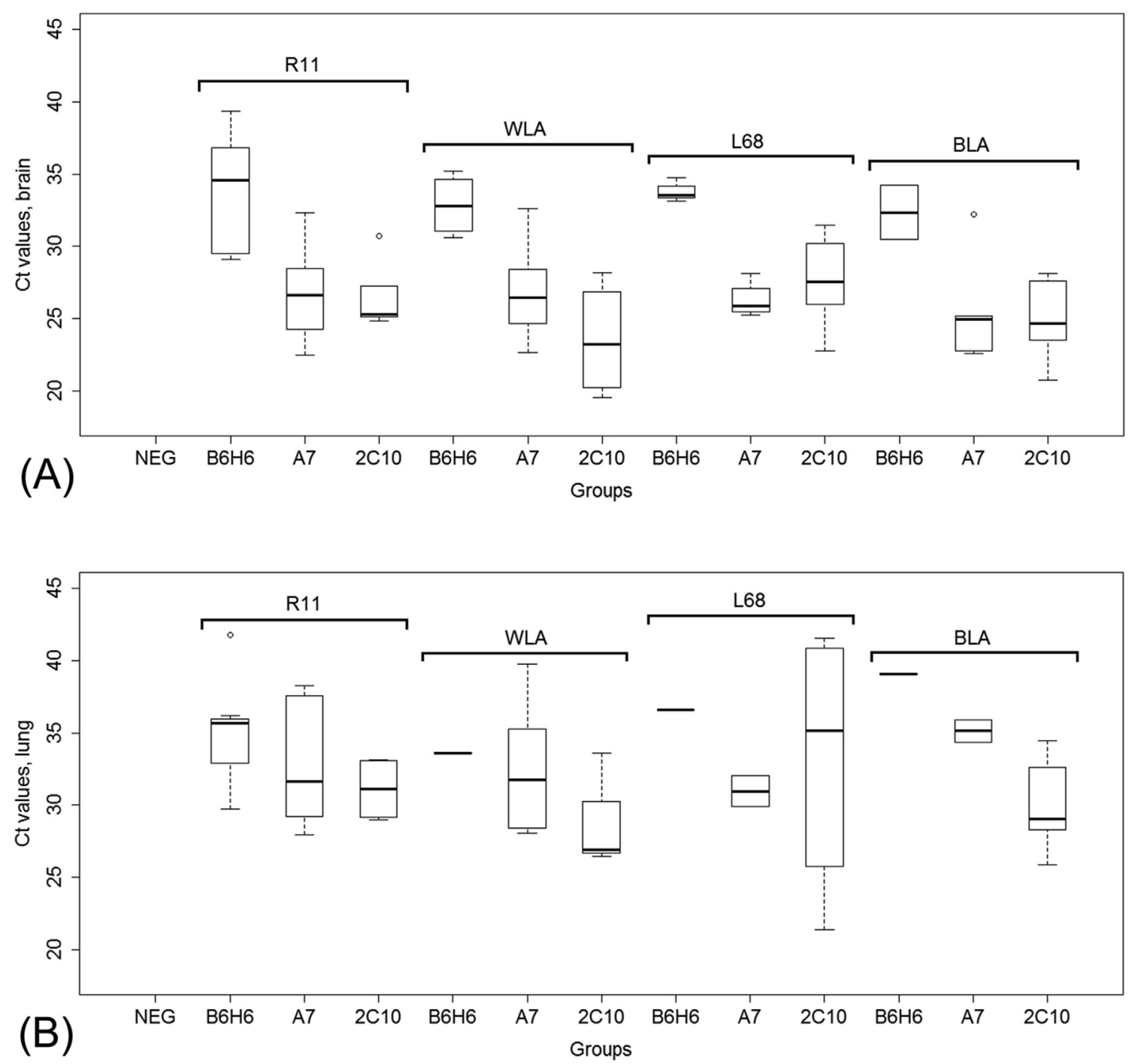

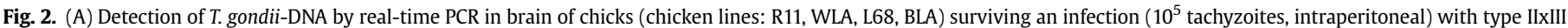

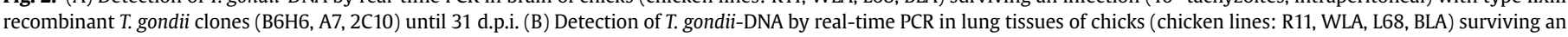
infection with type IIxIII recombinant $T$. gondii clones (B6H6, A7, 2C10) until 31 d.p.i.

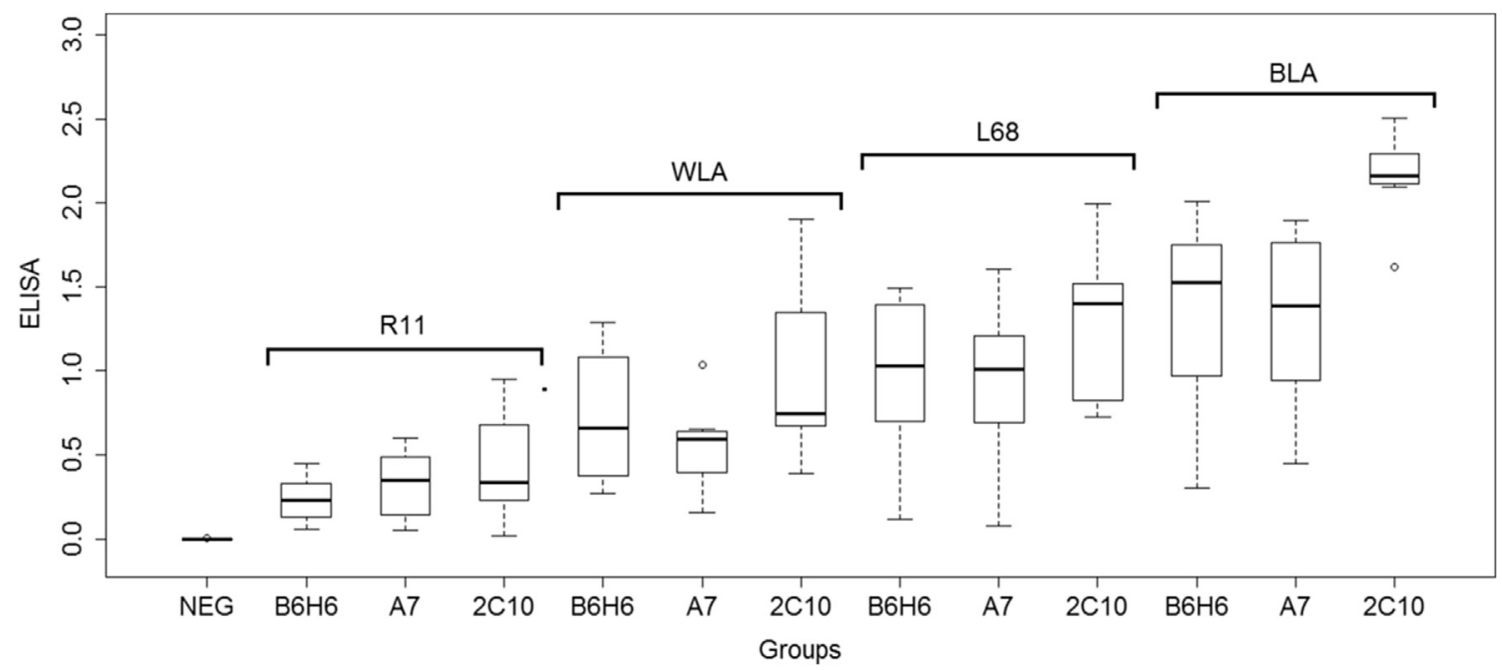

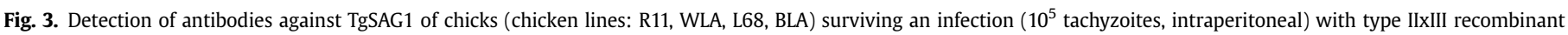
T. gondii clones (B6H6, A7, 2C10) until 31 d.p.i. 
higher antibody levels as compared to the negative control group (Wilcoxon rank sum test; $P<0.05$ ). With one exception (i.e. WLA chicks infected by clone A7), all groups of infected WLA, L68, or BLA chicks had significantly higher TG-SAG1 antibody levels than the infected R11 chicks (independent of the T. gondii clone used for infection; Wilcoxon rank sum test; $P<0.05$ ). The BLA chicks infected with clone 2C10 showed significantly higher antibody levels to TG-SAG1 as compared to any other group (Wilcoxon rank sum test; $P<0.05$ ). In addition, BLA chicks infected with B6H6 or A7 had significantly higher anti-TG-SAG1 levels than the WLA A7 infected group and - as mentioned above - all three R11 infected groups. L68 chicks infected with 2C10 had significantly higher TGSAG1-specific antibody levels than WLA chicks infected with A7 or B6H6 (Wilcoxon rank sum test; $P<0.05$ ).

\section{Discussion}

In the present study, the chicken virulence of natural type IIxIII recombinant $T$. gondii clones was assessed and compared to the mouse virulence of the respective clones. The $T$. gondii clones had been isolated from a naturally infected cat in Germany, in which most likely sexual recombination between a type II and a type III strain had occurred (Herrmann et al., 2012). For the chicken experiments, one-day old chicks of four genetically different chicken lines (R11, WLA, L68, BLA) were used. Mortality due to T. gondii infection occurred almost only in white layer lines, i.e. R11 and WLA, whilst brown layer chicks (L68, BLA) remained largely unaffected; increased mortality was almost exclusively restricted to infections with T. gondii clone 2C10. Only two of the T. gondii clones, clone 2C10 and A7, used for the chicken experiments showed the same virulence pattern in one-day old chicks as observed in BALB/C mice. In contrast, the $\mathrm{B} 6 \mathrm{H} 6$ clone, which had shown a high acute virulence for $\mathrm{BALB} / \mathrm{c}$ mice in a previous, and also in the present study, was largely avirulent in chicks, i.e. the mortality in infected groups was similar to that in controls. This is an important result because it has been a matter of debate whether virulence patterns observed in mice could be extrapolated to other host species.

Although mortality was low in most of the infected chicken lines, $T$. gondii infection could be demonstrated in almost all 2C10 infected and in a large proportion of the chicken lines when infected with $\mathrm{B} 6 \mathrm{H} 6$ or A7. The doses to induce mortality in chicks in our experiments differed largely from those sufficient to induce mortality in mice. For chicks, a dose of $10^{6}$ tachyzoite i.p. induced about $50 \%$ mortality, but only in white layer chicken lines and only for clone 2C10. In contrast, in our experiment with BALB/c mice, 100 tachyzoites i.p. of two of the three type IIxIII recombinant $T$. gondii clones $(2 \mathrm{C} 10, \mathrm{~B} 6 \mathrm{H} 6)$ were sufficient to induce $100 \%$ mortality in mice. Similar observations had been made in the past, indicating that much higher doses of $T$. gondii tachyzoites are needed to induce mortality in chickens using T. gondii isolates (Boch et al., 1966). In a more recent experiment, 10-day old chicks survived i.p. infections with doses of $10^{7}$ tachyzoites for 53 days and differences between strains were only observed at doses of $10^{8}$ tachyzoites and higher (Wang et al., 2015). Our findings therefore corroborate previous results and show that chickens are highly susceptible to $T$. gondii infection, but are largely resistant to developing clinical disease due to infection with the parasite (Dubey, 2010a).

Our results demonstrate that some, but not all of our type IIxIII recombinant $T$. gondii clones display a similar virulence phenotype in chickens as observed in mice. One of the clones (clone 2C10) showed mouse virulence only in the current study, in which it is different from the results obtained in the previous study (Herrmann et al., 2012). A possible explanation is that cell culture passages over several months may have modified this clone at the epigenetic level and thus increased its virulence to mice. It has been found that nucleosomes in the promotors of bradyzoite-specific genes were acetylated in low-passage tachyzoites from strains that differentiate more readily, but not in long-term cell culture adapted tachyzoites (Behnke et al., 2008).

Virulence of $T$. gondii in mice is mediated by a number of different ways. In a variety of studies, it has been shown that striking differences between $T$. gondii clonal lineages in terms of virulence are mainly linked to the capability of $T$. gondii to modulate the innate immune response of infected host cells. In-vitro experiments using chicken embryonic fibroblasts showed that type II and type III $T$. gondii as well as experimental sexual recombinants of T. gondii type II and III strains modulated infected chicken cells in a similar way as they did in mouse macrophages (Ong et al., 2011). In forward genetic studies on identifying quantitative trait loci (QTL) $21 \mathrm{~T}$. gondii type IIxIII recombinant clones were used, representing an experimentally induced F1 progeny of a type IIxIII cross. It was observed that genes encoding for proteins involved in host cell modulation are most likely located in particular regions of the T. gondii genome, i.e. on Chr Ia, VIIa, VIIb, and X. Not all loci, especially those on Chr Ia, could be traced back to those identified in previous studies. However, QTLs on Chr VIIa were most likely linked to the ROP18 and those on Chr VIIb to ROP16 genes, both coding for rhoptry proteins representing kinase-like proteins lacking catalytic activity (El Hajj et al., 2006).

ROP18 $8_{\text {I }}$ and ROP18 II (i.e. ROP18 proteins of type I or type II T. gondii) are known to mediate evasion from p47 GTPase-mediated killing of intracellular tachyzoites (Khaminets et al., 2010). ROP18 as a virulence factor is able to explain differences in virulence in mice but not in chickens because chickens are lacking p47 GTPases (Howard et al., 2011; Zhao et al., 2009). Our previous results showed that both clones which displayed a high virulence in mice in the present study (B6H6, 2C10), most likely possess a virulent ROP18 1 due to type II alleles in the CS3 marker or in the region upstream of the ROP18 gene (UPS) while the clone with intermediate virulence for mice (clone A7) processes most likely a ROP18 (Herrmann et al., 2012). Thus, differences in ROP18 genes may explain differences in virulence in mice, but not in chicks.

ROP16 was previously shown to have an effect in $T$. gondii infected chicken cells (Ong et al., 2011). The ROP16 gene is located at Chr VIIb and is known to interfere with the induction and sustenance of JAK/STAT signaling (Rosowski et al., 2011; Saeij et al., 2007; Yamamoto et al., 2009). ROP16 I and ROP16 III are reported to activate the JAK/STAT signaling and thus induce a Th2-like transcriptional program e.g. in murine macrophages (Jensen et al., 2011; Yamamoto et al., 2009). ROP16 I and ROP16 III $_{\text {II }}$ thus repress inflammation and this effect seems to be the same in mammalian and avian cells (Ong et al., 2011). The clones used in this study all showed type III alleles on Chr VIIb close to the ROP16 gene locus. Therefore, it is unlikely that ROP16 is responsible for the differences in chicken virulence observed in our experiments.

As determined by PCR-RFLP analysis, our clones do not differ in Chr X, which was shown to harbor potential virulence loci identified in QTL analyses with an infected chicken cell line (Ong et al., 2011). One of these virulence loci is close to the GRA15 gene, which is involved in NF-kB activation (Rosowski et al., 2011). GRA15 II $_{\text {(but not GRA15 I and GRA15 }}$ III) activates NF-kB and confers to an increased IL12 level. The second locus on Chr X identified in QTL analyses could not be linked to a previously known virulence gene (Ong et al., 2011). Our clones not virulent for chickens (B6H6, A7) and also the virulent ones (2C10) showed in PCR-RFLP analyses only type III alleles on Chr X.

Differences in mortality, but also in susceptibility to infection with $T$. gondii, between chicken lines were striking. While an increased mortality after infection with $T$. gondii clone 2C10 was almost limited to white layer chicks (R11, WLA), the numbers of 
DNA positive findings in white layer chicks, especially R11 chicks were much higher than in other chicks from brown layer lines. This occurred mainly in chicks infected with $\mathrm{B} 6 \mathrm{H} 6$ or $\mathrm{A} 7$, while the proportions of DNA positive findings were generally high in 2C10 infected chicks independent of the chicken line. Similar observations, suggesting differences in susceptibility between chickens with differences in their genetic background, were also observed for other diseases. Genetic variability for resistance to chicken coccidiosis caused by Eimeria tenella has been demonstrated (Bumstead and Millard, 1987; Clare et al., 1985) and was found to be associated with genes coding for MHC molecules (Brake et al., 1997; Caron et al., 1997; Clare et al., 1985; Lillehoj et al., 1989). Based on more recent QTL analyses also other immunity related candidate genes were in the discussion, potentially contributing to the resistance against coccidiosis (Pinard-van der Laan et al., 2009). These include a number of genes involved in apoptosis, inflammation as well as innate and adaptive immune response.

It has been shown that White Leghorns harboured significantly higher numbers of Heterakis gallinarum worms in intestines after experimental infection as compared to New Hampshire chickens (Gauly et al., 2008). In another study, Lohmann Brown chickens had a significantly higher worm burden (including Heterakis gallinarum, Capillaria spp., tapeworms and Ascaridia galli) than Lohmann Selected Leghorn (Kaufmann et al., 2011). There was some evidence that single nucleotide polymorphisms (SNPs) in immunological relevant genes could contribute to these differences in susceptibility (Lühken et al., 2011).

Parallel infection studies using the same chicken lines as in our experiments were performed using avian influenza virus. In these experiments, a lower mortality or a prolonged length of survival was observed in the brown layer lines (L68, BLA) as compared to the white layers (R11, WLA) (Blohm et al., 2016). Thus, also in these experiments, white layers seemed to be more vulnerable to infection with intracellular pathogens than brown layers.

Surprisingly, at $31 \mathrm{dpi}$, the antibody (IgY) reaction against $T$. gondii-SAG1, a major immunodominant antigen of $T$. gondii tachyzoites was much lower in R11 chicks, independent of the T. gondii clone used for the experiment. In WLA chicks, this was only the case in those infected with T. gondii clone A7. Since there was no significant difference in parasitic loads in brain and lung tissues between different chicken lines, this difference cannot be explained by differences in exposure to parasitic antigens. One possible explanation could be differences in the Th1/Th2 polarization between chicken lines. It is known that in birds, similar to mammals, the immune system is functionally polarized into so-called type 1 or type 2 immune pathways, i.e. a Th1/Th2 polarization exists also in birds (Degen et al., 2005). It might be that R11 as well as WLA chickens have a Th1-inclined immune response, i.e. an immune response in favour for inflammatory immunological reactions but not a Th2-inclined immune response in favour for antibody reactions. This in turn could also be responsible for increased mortality in white layers as the Th1-inclined immune response may cause immunopathology in addition to an efficient elimination of parasites. There are laboratory strains of mice (e.g. BALB/c), which are Th2-inclined compared to others (e.g., C57Bl/6) (Hemmers and Mowen, 2009) and T. gondii infected BALB/c mice were less likely affected by mortality than C57Bl/6 mice (McLeod et al., 1984, 1989). Although antibodies to TG-SAG1 inhibit the infection of host cells (Mineo et al., 1993), it is unlikely that antibodies are important in the control of a T. gondii infection (Kur et al., 2009). It is therefore not likely that lower antibody levels to TG-SAG1 are responsible for the higher mortality observed in R11 chicks.

In conclusion, studies in chicks and mice with natural type IIxIII recombinant $T$. gondii clones showed marked differences in virulence. A T. gondii clone, highly virulent in mouse showed no virulence in chicks, while another mouse virulent clone was also virulent in one of the tested chicken lines. The results show that progeny may arise from a sexual recombination between $T$. gondii clonal lineage strains resulting in different virulence for other animal species than mice. Differences in mortality and differences in antibody response observed in genetically different chicken lines, i.e. in white and brown layers, is an indication that the phylogenetic background of chicken lines is essential to understand reasons for the outcome of infection in chickens. In contrast, it seems that differences in laying performance between commercial lines and the non-selected conservation flocks within each of the phylogenetic groups of chickens do not affect mortality of one day old chicks due to toxoplasmosis.

\section{Conflict of interest}

The authors report no conflict of interest.

\section{Acknowledgements}

We thank Andrea Bärwald, Lieselotte Minke, Deborah Dymke and Aline Maksimov for their excellent technical assistance. G. Moré was supported by a Georg Forster research Fellowship of the Alexander von Humboldt Foundation, 53173 Bonn, Germany. This work was further supported by the German Federal Ministry of Education and Research (Toxonet01 and Toxonet02) by funds to G.S. (01KI0765 and 01KI1002F).

\section{References}

Ajzenberg, D., 2015. 1995-2015: it is time to celebrate 20 years of (intensive) genotyping of Toxoplasma gondii strains. Future Microbiol. 10, 689-691.

Ajzenberg, D., Banuls, A.L., Su, C., Dumetre, A., Demar, M., Carme, B., Darde, M.L. 2004. Genetic diversity, clonality and sexuality in Toxoplasma gondii. Int. J. Parasitol. 34, 1185-1196.

Ajzenberg, D., Banuls, A.L., Tibayrenc, M., Darde, M.L., 2002. Microsatellite analysis of Toxoplasma gondii shows considerable polymorphism structured into two main clonal groups. Int. J. Parasitol. 32, 27-38.

Araujo, F.G., Williams, D.M., Grumet, F.C., Remington, J.S., 1976. Strain-dependent differences in murine susceptibility to toxoplasma. Infect. Immun. 13, $1528-1530$.

Beauregard, M., Magwood, S.E., Bannister, G.L., Robertson, A., Boulanger, P., Ruckerbauer, G.M., Appel, M., 1965. A study of Toxoplasma infection in chickens and cats on a family farm. Can. J. Comp. Med. Vet. Sci. 29, 286-291.

Behnke, M.S., Radke, J.B., Smith, A.T., Sullivan Jr., W.J., White, M.W., 2008. The transcription of bradyzoite genes in Toxoplasma gondii is controlled by autonomous promoter elements. Mol. Microbiol. 68, 1502-1518.

Biering-Sorensen, U., 1956. Fjerkrætoxoplasmose. Om forekmsten af endemisk optrædende toxoplasmose (Toxoplasmosis gallinarium) i danske honsebesætninger. Nord. Vet. Med. 8, 140-164.

Blohm, U., Weigend, S., Preisinger, R., Beer, M., Hoffmann, D., 2016. Immunological competence of different domestic chicken breeds against avian influenza infection. Avian Dis. 60, 262-268.

Boch, J., Rommel, M., Weiland, G., Janitschke, K., Sommer, R., 1966. Experimentelle Toxoplasma-Infektion bei Legehennen. Berl. Münch. Tierarztl. Wochenschr 79, $352-356$.

Brake, D.A., Fedor, C.H., Werner, B.W., Miller, T.J., Taylor Jr., R.L., Clare, R.A., 1997. Characterization of immune response to Eimeria tenella antigens in a natural immunity model with hosts which differ serologically at the B locus of the major histocompatibility complex. Infect. Immun. 65, 1204-1210.

Bumstead, N., Millard, B., 1987. Genetics of resistance to coccidiosis: response of inbred chicken lines to infection by Eimeria tenella and Eimeria maxima. Br. Poult. Sci. 28, 705-715.

Caron, L.A., Abplanalp, H., Taylor, R.L.J., 1997. Resistence, susceptibility and immunity to Eimeria tenella in major histocompatibility (b) complex congenic lines. Poult. Sci. 76, 677-682.

Clare, R.A., Strout, R.G., Taylor Jr., R.L., Collins, W.M., Briles, W.E., 1985. Major histocompatibility (B) complex effects on acquired immunity to cecal coccidiosis. Immunogenetics 22, 593-599.

Cole, R.K., Hutt, F.B., 1973. Selection and heterosis in Cornell white leghorns: a review with special consideration of interstrain hybrids. Anim. Breed. Abstr. 41, 103-108.

Degen, W.G., Daal, N., Rothwell, L., Kaiser, P., Schijns, V.E., 2005. Th1/Th2 polarization by viral and helminth infection in birds. Vet. Microbiol. 105, 163-167.

Dobbin, C.A., Smith, N.C., Johnson, A.M., 2002. Heat shock protein 70 is a potential 
virulence factor in murine toxoplasma infection via immunomodulation of host NF-kappa B and nitric oxide. J. Immunol. 169, 958-965.

Dubey, J.P., 2002. A review of toxoplasmosis in wild birds. Vet. Parasitol. 106, $121-153$.

Dubey, J.P., 2010a. Toxoplasma gondii infections in chickens (Gallus domesticus): prevalence, clinical disease, diagnosis and public health significance. Zoonoses Public Health 57, 60-73.

Dubey, J.P., 2010b. Toxoplasmosis of Animals and Humans, second ed. CRC Press, Boca Rotan.

Dubey, J.P., Ruff, M.D., Camargo, M.E., Shen, S.K., Wilkins, G.L., Kwok, O.C., Thulliez, P., 1993. Serologic and parasitologic responses of domestic chickens after oral inoculation with Toxoplasma gondii oocysts. Am. J. Vet. Res. 54, $1668-1672$

Dubey, J.P., Webb, D.M., Sundar, N., Velmurugan, G.V., Bandini, L.A., Kwok, O.C., Su, C., 2007. Endemic avian toxoplasmosis on a farm in Illinois: clinical disease, diagnosis, biologic and genetic characteristics of Toxoplasma gondii isolates from chickens (Gallus domesticus), and a goose (Anser anser). Vet. Parasitol. 148, 207-212.

El Hajj, H., Demey, E., Poncet, J., Lebrun, M., Wu, B., Galeotti, N., Fourmaux, M.N., Mercereau-Puijalon, O., Vial, H., Labesse, G., Dubremetz, J.F., 2006. The ROP2 family of Toxoplasma gondii rhoptry proteins: proteomic and genomic characterization and molecular modeling. Proteomics 6, 5773-5784.

Erichsen, S., Harboe, A., 1953. Toxoplasmosis in chickens. I. An epidemic outbreak of toxoplasmosis in a chicken flock in South-Eastern Norway. Acta Pathol. Microbiol. Scand. 33, 56-71.

Fentress, S.J., Behnke, M.S., Dunay, I.R., Mashayekhi, M., Rommereim, L.M., Fox, B.A., Bzik, D.J., Taylor, G.A., Turk, B.E., Lichti, C.F., Townsend, R.R., Qiu, W., Hui, R., Beatty, W.L., Sibley, L.D., 2010. Phosphorylation of immunity-related GTPases by a Toxoplasma gondii-secreted kinase promotes macrophage survival and virulence. Cell. Host Microbe 8, 484-495.

Frankhauser, R., 1951. Schweiz. Arch. Tierheilkd. Toxoplasmose beim Huhn 93, $823-828$.

Gauly, M., Kanan, A., Brandt, H., Weigend, S., Moors, E., Erhardt, G., 2008. Genetic resistance to Heterakis gallinarum in two chicken layer lines following a single dose infection. Vet. Parasitol. 155, 74-79.

Geißler, H., 1952. Toxoplasmose bei Hühnern. Dtsch. Tierarztl. Wochenschr 59, $166-168$.

Geissler, H., 1955. Untersuchungen über die Toxoplasmose beim Huhn unter besonderer Berücksichtigung der Serodiagnostik. Zentralblatt fur Veterinarmedizin 2, 251-283.

Goodwin, M.A., Dubey, J.P., Hatkin, J., 1994. Toxoplasma gondii peripheral neuritis in chickens. J. Vet. Diagn. Invest 6, 382-385.

Granevitze, Z., Hillel, J., Feldman, M., Six, A., Eding, H., Weigend, S., 2009. Genetic structure of a wide-spectrum chicken gene pool. Anim. Genet. 40, 686-693.

Hartmann, W., 1987. In: Genetic Aspects of Resistance to Avian Leukosis and Marek's Disease. Annual National Breeder's Roundtable, Saint Louis, MO, USA, pp. 34-72.

Hemmers, S., Mowen, K.A., 2009. T(H)2 bias: mina tips the balance. Nat. Immunol, 10, 806-808.

Hepding, L., 1939. Ueber Toxoplasmen (Toxoplasma gallinarum n. sp.) in der Retina eines Huhnes und über deren Beziehung zur Hühnerlähmung. Zeitschrift für Infektionskrankheiten 4, 109-116.

Herrmann, D.C., Barwald, A., Maksimov, A., Pantchev, N., Vrhovec, M.G., Conraths, F.J., Schares, G., 2012. Toxoplasma gondii sexual cross in a single naturally infected feline host: generation of highly mouse-virulent and avirulent clones, genotypically different from clonal types I, II and III. Vet. Res. 43, 39.

Herrmann, D.C., Pantchev, N., Vrhovec, M.G., Barutzki, D., Wilking, H., Frohlich, A., Luder, C.G., Conraths, F.J., Schares, G., 2010. Atypical Toxoplasma gondii genotypes identified in oocysts shed by cats in Germany. Int. J. Parasitol. 40, 285-292.

Howard, J.C., Hunn, J.P., Steinfeldt, T., 2011. The IRG protein-based resistance mechanism in mice and its relation to virulence in Toxoplasma gondii. Curr. Opin. Microbiol. 14, 414-421.

Jacobs, L., Melton, M.L., 1966. Toxoplasmosis in chickens. J. Parasitol. 52, 1158-1162.

Jensen, K.D., Wang, Y., Wojno, E.D., Shastri, A.J., Hu, K., Cornel, L., Boedec, E., Ong, Y.C., Chien, Y.H., Hunter, C.A., Boothroyd, J.C., Saeij, J.P., 2011. Toxoplasma polymorphic effectors determine macrophage polarization and intestinal inflammation. Cell Host Microbe 9, 472-483.

Kaneto, C.N., Costa, A., Paulillo, A.C., Moraes, F.R., Murakami, T.O., Meireles, M.V., 1997. Experimental toxoplasmosis in broiler chicks. Vet. Parasitol. 69, 203-210.

Kaufmann, F., Das, G., Preisinger, R., Schmutz, M., Konig, S., Gauly, M., 2011. Genetic resistance to natural helminth infections in two chicken layer lines. Vet. Parasitol. 176, 250-257.

Khaminets, A., Hunn, J.P., Konen-Waisman, S., Zhao, Y.O., Preukschat, D., Coers, J., Boyle, J.P., Ong, Y.C., Boothroyd, J.C., Reichmann, G., Howard, J.C., 2010. Coordinated loading of IRG resistance GTPases on to the Toxoplasma gondii parasitophorous vacuole. Cell Microbiol. 12, 939-961.

Khan, A., Taylor, S., Ajioka, J.W., Rosenthal, B.M., Sibley, L.D., 2009. Selection at a single locus leads to widespread expansion of Toxoplasma gondii lineages that are virulent in mice. PLoS Genet. 5 e1000404.

Kulasiri, C.D., 1965. Infection of chicken with avirulent Toxoplasma gondii. Exp. Parasitol. 17, 65-68.

Kur, J., Holec-Gasior, L., Hiszczynska-Sawicka, E., 2009. Current status of toxoplasmosis vaccine development. Expert Rev. Vaccines 8, 791-808.
Lieboldt, M.A., Halle, I., Frahm, J., Schrader, L., Baulain, U., Henning, M., Preisinger, R., Danicke, S., Weigend, S., 2015. Phylogenic versus selection effects on growth development, egg laying and egg quality in purebred laying hens. Eur. Poult. Sci. 79 .

Lillehoj, H.S., Ruff, M.D., Bacon, L.D., Lamont, S.J., Jeffers, T.K., 1989. Genetic control of immunity to Eimeria tenella. Interaction of MHC genes and non-MHC linked genes influences levels of disease susceptibility in chickens. Vet. Immunol. Immunopathol. 20, 135-148.

Lühken, G., Gauly, M., Kaufmann, F., Erhardt, G., 2011. Association study in naturally infected helminth layers shows evidence for influence of interferon-gamma gene variants on Ascaridia galli worm burden. Vet. Res. 42, 84.

Lyimo, C.M., Weigend, A., Msoffe, P.L., Eding, H., Simianer, H., Weigend, S., 2014. Global diversity and genetic contributions of chicken populations from African, Asian and European regions. Anim. Genet. 45, 836-848.

Maksimov, P., Buschtöns, S., Herrmann, D.C., Conraths, F.J., Görlich, K., Tenter, A.M. Dubey, J.P., Nagel-Kohl, U., Thoms, B., Bötcher, L., Kühne, M., Schares, G., 2011. Serological survey and risk factors for Toxoplasma gondii in domestic ducks and geese in lower saxony. Ger. Vet. Parasitol. 182, 140-149.

McLeod, R., Eisenhauer, P., Mack, D., Brown, C., Filice, G., Spitalny, G., 1989. Immune responses associated with early survival after peroral infection with Toxoplasma gondii. J. Immunol. 142, 3247-3255.

McLeod, R., Estes, R.G., Mack, D.G., Cohen, H., 1984. Immune response of mice to ingested Toxoplasma gondii: a model of toxoplasma infection acquired by ingestion. J. Infect. Dis. 149, 234-244.

Mineo, J.R., McLeod, R., Mack, D., Smith, J., Khan, I.A., Ely, K.H., Kasper, L.H., 1993. Antibodies to Toxoplasma gondii major surface protein (SAG-1, P30) inhibit infection of host cells and are produced in murine intestine after peroral infection. J. Immunol. 150, 3951-3964.

Ong, Y.C., Boyle, J.P., Boothroyd, J.C., 2011. Strain-dependent host transcriptional responses to Toxoplasma infection are largely conserved in mammalian and avian hosts. PLoS ONE 6, e26369.

Peixoto, L., Chen, F., Harb, O.S., Davis, P.H., Beiting, D.P., Brownback, C.S., Ouloguem, D., Roos, D.S., 2010. Integrative genomic approaches highlight a family of parasite-specific kinases that regulate host responses. Cell Host Microbe 8, 208-218.

Pinard-van der Laan, M.H., Bed'hom, B., Coville, J.L., Pitel, F., Feve, K., Leroux, S., Legros, H., Thomas, A., Gourichon, D., Reperant, J.M., Rault, P., 2009. Microsatellite mapping of QTLs affecting resistance to coccidiosis (Eimeria tenella) in a Fayoumi $\times$ White Leghorn cross. BMC Genomics 10, 31 .

Robben, P.M., Mordue, D.G., Truscott, S.M., Takeda, K., Akira, S., Sibley, L.D., 2004. Production of IL-12 by macrophages infected with Toxoplasma gondii depends on the parasite genotype. J. Immunol. 172, 3686-3694.

Rosowski, E.E., Lu, D., Julien, L., Rodda, L., Gaiser, R.A., Jensen, K.D., Saeij, J.P., 2011. Strain-specific activation of the NF-kappaB pathway by GRA15, a novel Toxoplasma gondii dense granule protein. J. Exp. Med. 208, 195-212.

Saeij, J.P., Boyle, J.P., Coller, S., Taylor, S., Sibley, L.D., Brooke-Powell, E.T., Ajioka, J.W., Boothroyd, J.C., 2006. Polymorphic secreted kinases are key virulence factors in toxoplasmosis. Science 314, 1780-1783.

Saeij, J.P., Coller, S., Boyle, J.P., Jerome, M.E., White, M.W., Boothroyd, J.C., 2007. Toxoplasma co-opts host gene expression by injection of a polymorphic kinase homologue. Nature 445, 324-327.

Schellner, H., Vollbrechtshausen, R., 1955. Über einen Fall von Toxoplasmose bei einem Junghuhn. Monatshefte Tierheilkunde 7, 295-297.

Schulte, F., 1954. Toxoplasmose-Encephalitis beim Geflügel. Dtsch. Tierärztl. Wochenschr. 61, 481-484.

Shwab, E.K., Zhu, X.Q., Majumdar, D., Pena, H.F., Gennari, S.M., Dubey, J.P., Su, C., 2014. Geographical patterns of Toxoplasma gondii genetic diversity revealed by multilocus PCR-RFLP genotyping. Parasitology 141, 453-461.

Simitch, T., Savin, Z., Bordjochki, A., Petrovitch, Z., Tomanovitch, B., 1961. Infection of fowl with Toxoplasma gondii by the oral route. (Preliminary observation). Arch. Inst. Pasteur Alger. 39, 441-447.

Steinfeldt, T., Konen-Waisman, S., Tong, L., Pawlowski, N., Lamkemeyer, T., Sibley, L.D., Hunn, J.P., Howard, J.C., 2010. Phosphorylation of mouse immunityrelated GTPase (IRG) resistance proteins is an evasion strategy for virulent Toxoplasma gondii. PLoS Biol. 8, e1000576.

Su, C., Khan, A., Zhou, P., Majumdar, D., Ajzenberg, D., Darde, M.L., Zhu, X.Q. Ajioka, J.W., Rosenthal, B.M., Dubey, J.P., Sibley, L.D., 2012. Globally diverse Toxoplasma gondii isolates comprise six major clades originating from a small number of distinct ancestral lineages. Proc. Natl. Acad. Sci. U. S. A. 109, 5844-5849.

Su, C., Zhang, X., Dubey, J.P., 2006. Genotyping of Toxoplasma gondii by multilocus PCR-RFLP markers: a high resolution and simple method for identification of parasites. Int. J. Parasitol. 36, 841-848.

Talabani, H., Asseraf, M., Yera, H., Delair, E., Ancelle, T., Thulliez, P., Brezin, A.P., Dupouy-Camet, J., 2009. Contributions of immunoblotting, real-time PCR, and the Goldmann-Witmer coefficient to diagnosis of atypical toxoplasmic retinochoroiditis. J. Clin. Microbiol. 47, 2131-2135.

Taylor, S., Barragan, A., Su, C., Fux, B., Fentress, S.J., Tang, K., Beatty, W.L., Hajj, H.E., Jerome, M., Behnke, M.S., White, M., Wootton, J.C., Sibley, L.D., 2006. A secreted serine-threonine kinase determines virulence in the eukaryotic pathogen Toxoplasma gondii. Science 314, 1776-1780.

VanWormer, E., Miller, M.A., Conrad, P.A., Grigg, M.E., Rejmanek, D., Carpenter, T.E., Mazet, J.A., 2014. Using molecular epidemiology to track Toxoplasma gondii from terrestrial carnivores to marine hosts: implications for public health and conservation. PLoS Negl. Trop. Dis. 8, e2852. 
Wang, S., Zhao, G.W., Wang, W., Zhang, Z.C., Shen, B., Hassan, I.A., Xie, Q., Yan, R.F., Song, X.K., Xu, L.X., Li, X.R., 2015. Pathogenicity of five strains of Toxoplasma gondii from different animals to chickens. Korean J. Parasitol. 53, 155-162.

Yamamoto, M., Standley, D.M., Takashima, S., Saiga, H., Okuyama, M., Kayama, H. Kubo, E., Ito, H., Takaura, M., Matsuda, T., Soldati-Favre, D., Takeda, K., 2009. A single polymorphic amino acid on Toxoplasma gondii kinase ROP16 determines the direct and strain-specific activation of Stat3. J. Exp. Med. 206, 2747-2760.

Zhao, Y.O., Rohde, C., Lilue, J.T., Könen-Waisman, S., Khaminets, A., Hunn, J.P., Howard, J.C., 2009. Toxoplasma gondii and the Immunity-Related GTPase (IRG) resistance system in mice: a review. Memorias do Institudo Oswaldo Cruz 104, 234-240. 